\title{
Apolipoprotein-E forms dimers in human frontal cortex and hippocampus
}

\author{
David A Elliott ${ }^{1}$, Glenda M Halliday ${ }^{1,2}$, Brett Garner ${ }^{1,3^{*}}$
}

\begin{abstract}
Background: Apolipoprotein-E (apoE) plays important roles in neurobiology and the apoE4 isoform increases risk for Alzheimer's disease (AD). ApoE3 and apoE2 are known to form disulphide-linked dimers in plasma and cerebrospinal fluid whereas apoE4 cannot form these dimers as it lacks a cysteine residue. Previous in vitro research indicates dimerisation of apoE3 has a significant impact on its functions related to cholesterol homeostasis and amyloid-beta peptide degradation. The possible occurrence of apoE dimers in cortical tissues has not been examined and was therefore assessed. Human frontal cortex and hippocampus from control and AD post-mortem samples were homogenised and analysed for apoE by western blotting under both reducing and non-reducing conditions.

Results: In apoE3 homozygous samples, $\sim 12 \%$ of apoE was present as a homodimer and $\sim 2 \%$ was detected as a $43 \mathrm{kDa}$ heterodimer. The level of dimerisation was not significantly different when control and AD samples were compared. As expected, these dimerised forms of apoE were not detected in apoE4 homozygous samples but were detected in apoE3/4 heterozygotes at a level approximately 60\% lower than seen in the apoE3 homozygous samples. Similar apoE3 dimers were also detected in lysates of SK-N-SH neuroblastoma cells and in freshly prepared rabbit brain homogenates. The addition of the thiol trapping agent, iodoacetamide, to block reactive thiols during both human and rabbit brain sample homogenisation and processing did not reduce the amount of apoE homodimer recovered. These data indicate that the apoE dimers we detected in the human brain are not likely to be post-mortem artefacts.
\end{abstract}

Conclusion: The identification of disulphide-linked apoE dimers in human cortical and hippocampal tissues represents a distinct structural difference between the apoE3 and apoE4 isoforms that may have functional consequences.

\section{Background}

Apolipoprotein-E (apoE) is a $\sim 34 \mathrm{kDa}$ protein that plays important roles in lipid transport and neurobiology $[1,2]$. In humans, apoE exists as three major isoforms apoE2, apoE3 and apoE4 which differ in their Cys/Arg composition at positions 112 and 158. ApoE2 contains $\mathrm{Cys}^{112}$, Cys ${ }^{158}$; apoE3 contains $\mathrm{Cys}^{112}, \mathrm{Arg}^{158}$; and apoE4 contains $\mathrm{Arg}^{112}, \mathrm{Arg}^{158}$ [3]. ApoE4 is a major genetic risk factor for late-onset Alzheimer's disease (AD) whereas apoE2 is associated with decreased AD risk $[4,5]$. ApoE in the CNS is primarily produced by astrocytes, although microglia and neurons may also contribute under certain circumstances [1,6-8,8-11].

\footnotetext{
* Correspondence: b.garner@powmri.edu.au

${ }^{1}$ Prince of Wales Medical Research Institute, Randwick NSW 2031, Australia
}

ApoE participates in several biological processes that extend beyond lipid transport and include immunoregulation, oxidative stress, stabilization of neuronal microtubules, nerve regeneration, apoptosis and amyloid-beta (A $\beta)$ peptide clearance and degradation [11-20]. Despite intense research into the diverse biological functions of apoE, the precise mechanism by which the apoE4 isoform increases $A D$ risk remains to be fully elucidated. However, many differences between apoE3 and apoE4 structure and function have been reported that are potentially relevant to AD. These include: reduced lipidbinding capacity of apoE4 due to isoform-specific domain interactions [21], lipidated apoE4 has a lower affinity for $A \beta[22,23]$, apoE4 is less efficient at stabilizing microtubules [14], apoE4 exhibits weaker antioxidant activity [13] and apoE4 is structurally less stable
Ciomed Central 
$[24,25]$ when compared to apoE3. It is also clear that the proteolytic fragmentation of apoE in the human brain is isoform-dependent [26-29]. In addition, a significant proportion of apoE3 (and apoE2) is present in plasma, CSF and astrocyte conditioned media as a disulfidelinked homodimer and as an apoE-apoA-II heterodimer [30-34]. This may be important as apoE4 lacks Cys and cannot form disulphide-linked dimers. In vitro studies have shown that compared to apoE monomers, apoE dimers possess significantly altered functional properties in terms of their capacity to regulate cellular cholesterol efflux and to interact with $A \beta$ [30,35-38]. This further underscores the importance of probing for the possible occurrence of apoE dimers in the human brain. In the present study we demonstrate that disulphide-linked apoE homodimers and heterodimers are present in the human cortex and hippocampus. In addition, we show that apoE dimerisation was not affected by the presence of $\mathrm{AD}$.

\section{Results}

\section{ApoE3 forms disulfide-linked dimers in the human brain} It is established that apoE3 forms disulphide-linked homodimers and apoE3-apoA-II heterodimers in human plasma and CSF [30,33]. As apoE4 lacks Cys it cannot form disulphide bonds. Whether apoE3 exists in a dimeric state in human brain tissue is unknown and we therefore focused on this issue. Western blot analysis of TBS-soluble brain homogenates derived from the hippocampus of a control apoE3/3 subject indicated a clear apoE3 homodimer when the sample was run under non-reducing conditions (Fig 1A). The homodimer was detected at $\sim 95 \mathrm{kDa}$ (as opposed to the predicted $\sim 68 \mathrm{kDa}$ ) which is consistent with previous data $[30,33]$. ApoE contains a major cut site for thrombin in the linker region [39]. Due to the high proteolytic specificity of thrombin $[40,41]$, it was used here to further confirm the identification of the $\sim 95$ $\mathrm{kDa}$ band as an apoE homodimer. The putative apoE3 homodimer was removed after incubation with thrombin, as predicted, further confirming that the $\sim 95 \mathrm{kDa}$ band is not likely to be due to non-specific binding of the antibody used.

Incubation of the homogenate in the presence of heatinactivated thrombin resulted in a partial loss of the apoE dimer which suggests that endogenous proteases may also degrade apoE (Fig 1A). A band of relatively lower intensity was also observed at $\sim 43 \mathrm{kDa}$ in the non-incubated apoE3 control condition. This is consistent with the apoE-apoA-II heterodimer previously detected in human plasma and CSF [30,33]. A series of apoE fragments was also detected with a major band at $\sim 24 \mathrm{kDa}$. This is in close agreement to our previous observations [29].
Additional hippocampal and frontal cortex homogenates from control apoE3/3 donors were analysed and this revealed that the apoE3 homodimer was present in all samples and accounted for $8.3 \pm 0.9 \%$ (mean \pm SE, $\mathrm{n}=6$ ) of the total apoE present in the hippocampus and $16.5 \% \pm 4.1 \%$ (mean $\pm \mathrm{SE}, \mathrm{n}=7$ ) of the total apoE present in the frontal cortex (Fig 2). Although the percentage of apoE present as the homodimer was on average increased in the frontal cortex, this difference did not reach statistical significance. We also analysed frontal cortex and hippocampus derived from apoE3/3 $\mathrm{AD}$ samples and found that apoE3 dimers were detected in all AD samples and were identical to those in the control samples (Fig 1B). There was no significant difference regarding the proportion of apoE that was present in the dimerised form when frontal cortex from the two groups were compared (Control $16.5 \pm 4.1 \%$, mean $\pm \mathrm{SE}, \mathrm{n}=7$; $\mathrm{AD} 11.2 \pm 2.4 \%$, mean $\pm \mathrm{SE}, \mathrm{n}=5$ ).

We also used an additional rigorous extraction protocol employing extraction buffer that contained the detergent Triton-X100. This was done in order to maximise recovery of apoE that may be associated with TBSinsoluble material. Both the control and AD samples were found to contain apoE homodimers when samples were extracted in detergent-containing buffer (Fig 3). These data are very similar to the results obtained with the TBS-soluble homogenates (Fig 1).

As predicted, apoE dimers were not detected in any of the 7 apoE4/4 AD samples analyzed (Fig 4, see also Fig 1C). Analysis of heterozygous apoE3/4 AD samples revealed a significant $61 \%$ reduction in the percentage of apoE3 present as homodimer as compared to apoE3/3 homozygous AD samples (AD 3/3 $11.2 \pm 2.4 \%$, mean \pm $\mathrm{SE}, \mathrm{n}=5 ; \mathrm{AD} 3 / 44.4 \% \pm 0.6$, mean $\pm \mathrm{SE}, \mathrm{n}=5 ; \mathrm{p}<$ 0.03). Representative blots from heterozygous apoE3/4 AD samples are shown (Fig 5).

\section{ApoE3 forms disulphide-linked dimers in human SK-N-SH neurons and rabbit brain}

One potential issue that arises in the analysis of protein modifications in human post-mortem material is the potential for artifactual changes to be induced by postmortem interval (PMI). Even though clear $\sim 95 \mathrm{kDa}$ and $\sim 43 \mathrm{kDa}$ apoE dimers were detected in apoE3 AD homozygous samples with a post-mortem delay of as short as $1 \mathrm{~h}$ (and PMI for the AD sample shown in Fig $1 \mathrm{~B}$ was only $7 \mathrm{~h}$ ), we also probed for apoE dimers in human neuroblastoma cell lysates and freshly harvested rabbit brain. The human SK-N-SH neuroblastoma cell line expresses the $A P O E \& 3 / \varepsilon 3$ genotype $[42,43]$ and synthesizes large amounts of apoE under serum starved conditions [11], whereas rabbits are one of the few nonhuman species known to contain an apoE Cys ${ }^{112}$ residue [31]. 


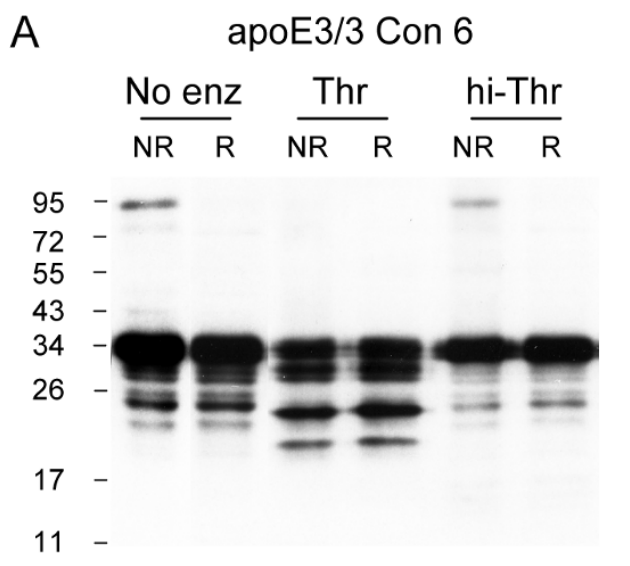

B

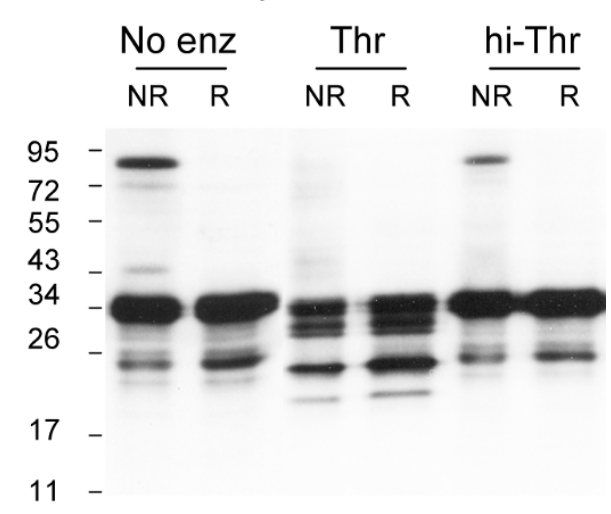

C apoE4/4 AD 11

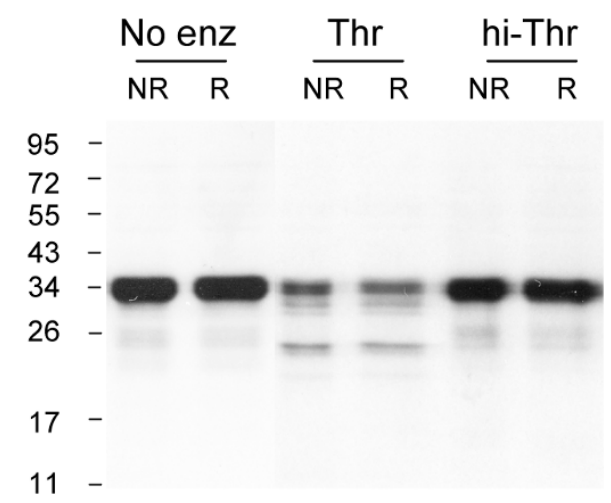

Figure 1 ApoE3 dimers are present in human hippocampus. The presence of disulphide-linked dimers of apoE were detected by analysing samples under both non-reducing "NR" and reducing " $\mathrm{R}$ " SDS-PAGE conditions. The susceptibility of dimers to thrombin cleavage was tested using three different conditions; storage at $-80^{\circ}$ $\mathrm{C}$ with no enzyme added "No enz", incubation at $37^{\circ} \mathrm{C}$ in the presence of thrombin "Thr" or heat-inactivated thrombin "hi-Thr". TBS-soluble fractions from control apoE3 (A), AD apoE3 (B) and AD apoE4 (C) homozygous hippocampal tissue samples were analysed. Western blotting was performed using goat anti-apoE polyclonal antibody. The human brain samples (Con $n=1, A D n=2$ ) are identified according to the Case \# code given in Table 1.

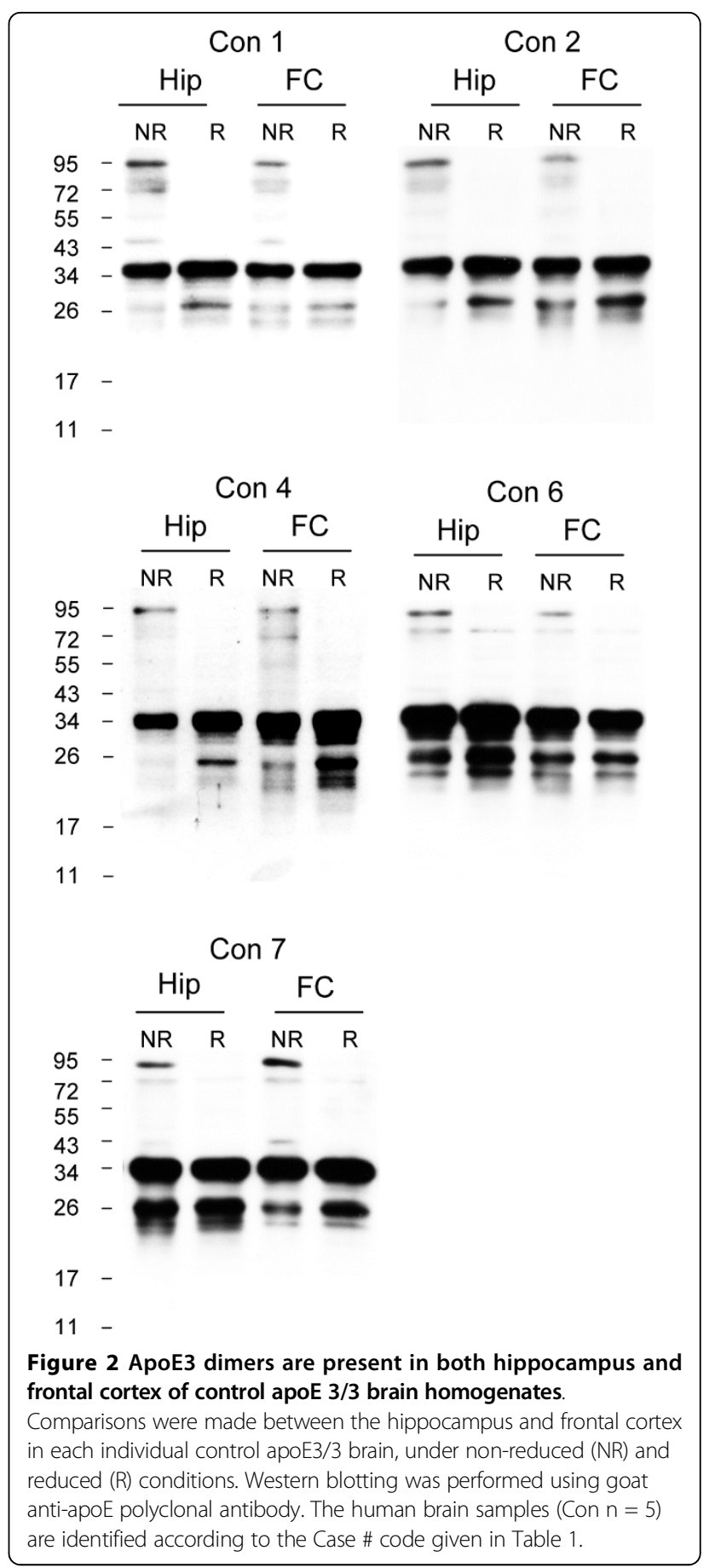

Analysis of SK-N-SH cell lysates under non-reducing conditions revealed the presence of the $\sim 95 \mathrm{kDa}$ apoE homodimer and a more prominent (than human brain) $\sim 43 \mathrm{kDa}$ heterodimer (Fig 6A). Since the $\sim 43 \mathrm{kDa}$ dimer could theoretically represent a disulphide-linked apoE $\mathrm{N}$-terminal domain homodimer (a predicted $\mathrm{MW}$ of $\sim 44 \mathrm{kDa}$ ), we used a $\mathrm{C}$-terminal specific monoclonal antibody in this experiment and the detection of the 

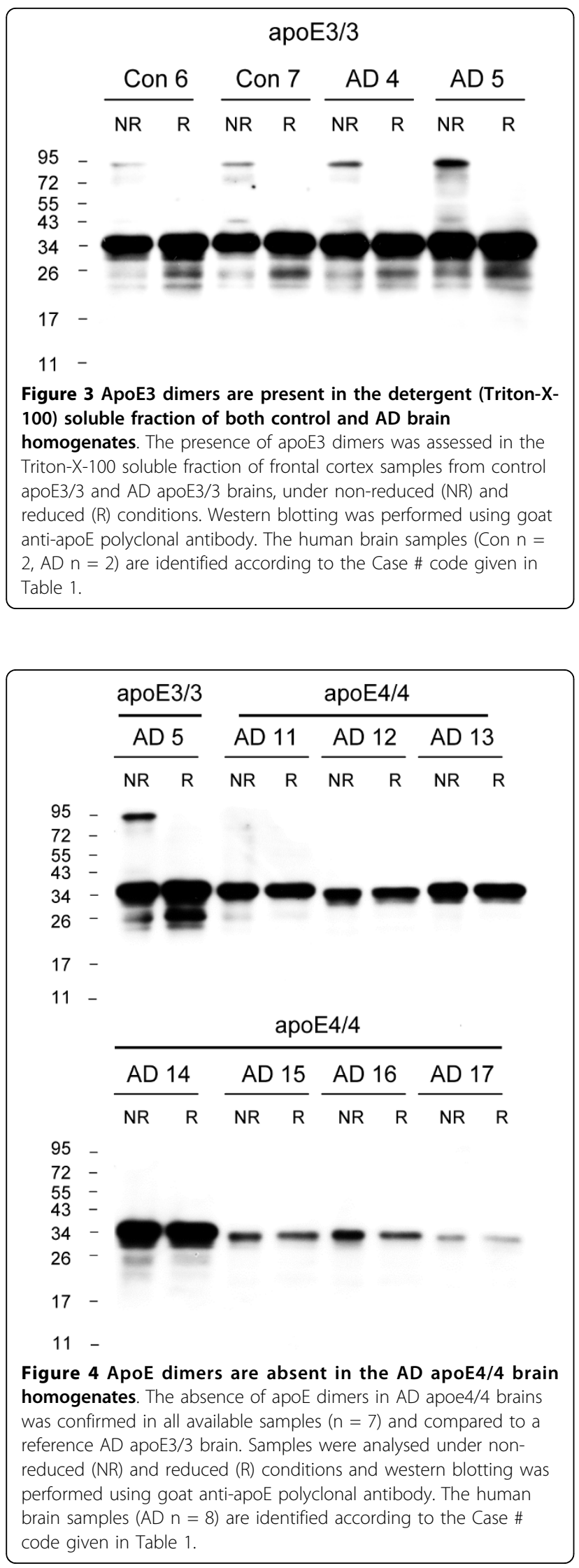

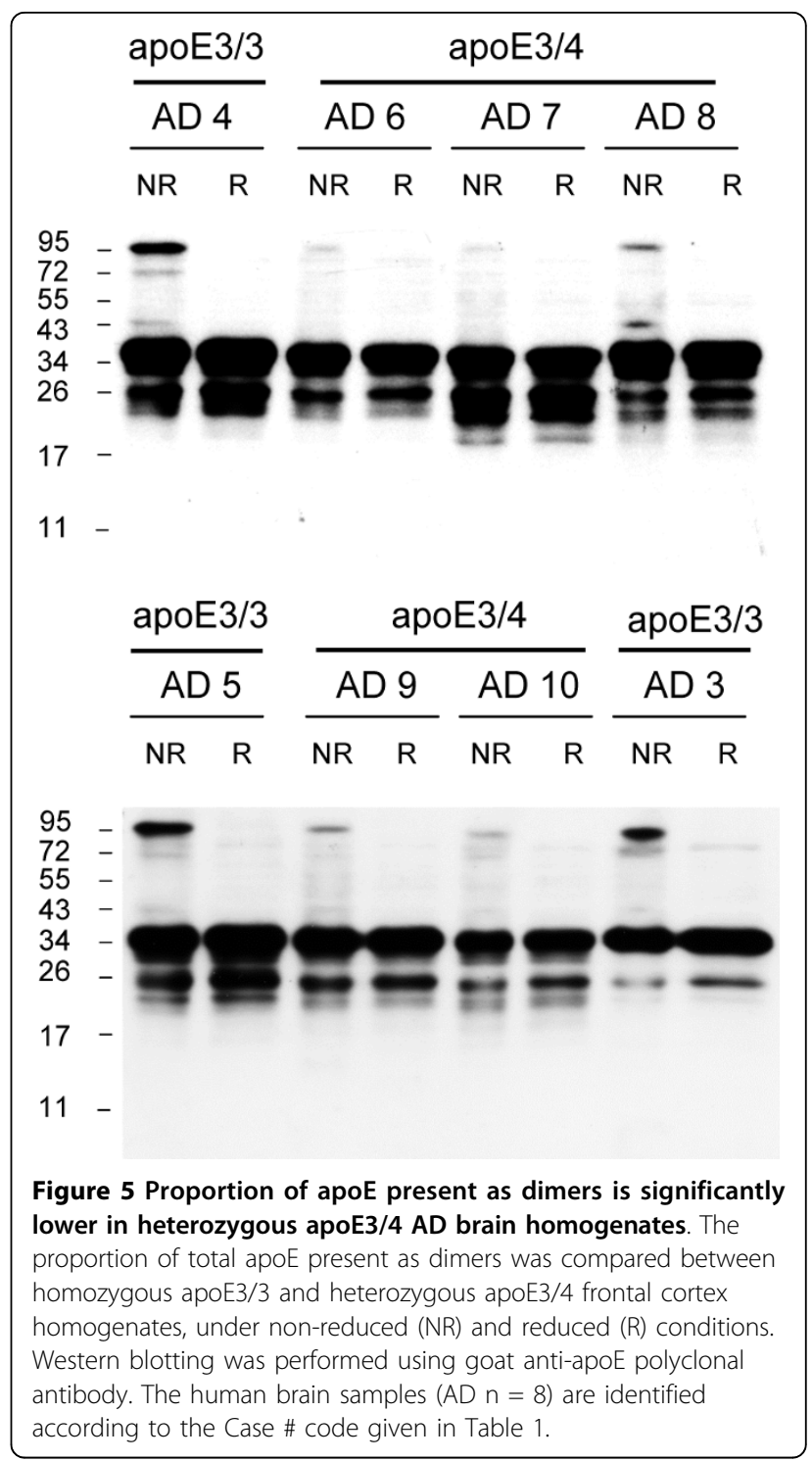

$\sim 43 \mathrm{kDa}$ band indicates an intact $\mathrm{C}$-terminus. This rules out the presence of disulphide-linked $\mathrm{N}$-terminal domain homodimer. The $\sim 43 \mathrm{kDa}$ band may represent an apoE3-apoA-II heterodimer as has been previously described in human plasma and CSF [30,33].

In the analysis of rabbit frontal cortex, the brain was dissected and processed immediately at the time of death to eliminate post-mortem delay and all measures were taken to prevent serum and CSF contamination (see Materials and Methods). An apoE band at $\sim 95 \mathrm{kDa}$ was also detected in rabbit brain when samples were run in the non-reduced state (Fig 6B), again indicating that apoE containing $\mathrm{Cys}^{112}$ does form a homodimer in the brain.

To address the possibility that the observed apoE dimerisation may occur during tissue homogenization and processing for electrophoresis, freshly prepared 


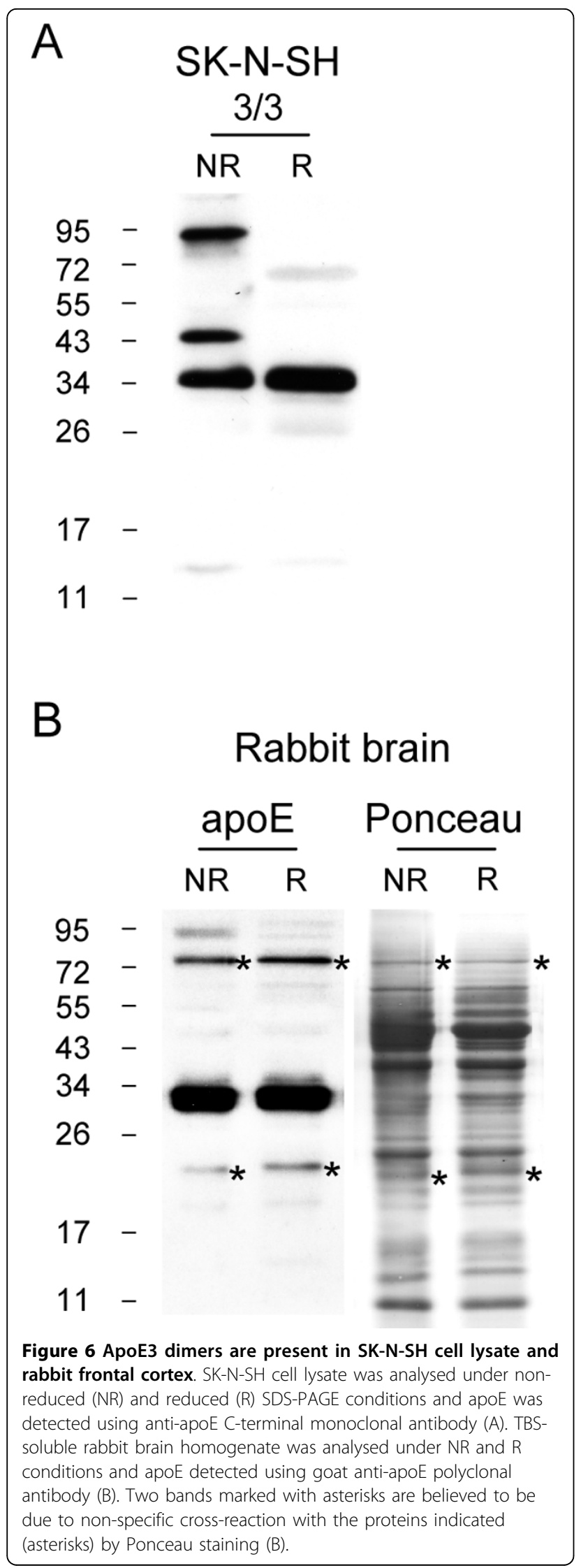

rabbit brain and frozen human frontal cortex tissue (AD apoE3/3) were homogenized in buffer containing the thiol trapping agent iodoacetamide. Homogenization was also performed using a detergent-rich lysis buffer to delipidate apoE-containing lipoproteins and help prevent the possibility of dimers forming spontaneously on lipoprotein particles during homogenization and processing. The presence of $100 \mathrm{mM}$ iodoacetamide did not result in a decrease in apoE homodimer levels in either rabbit or human brain tissue (Fig 7A). The thiol-trapping efficiency of $100 \mathrm{mM}$ iodoacetamide was confirmed by

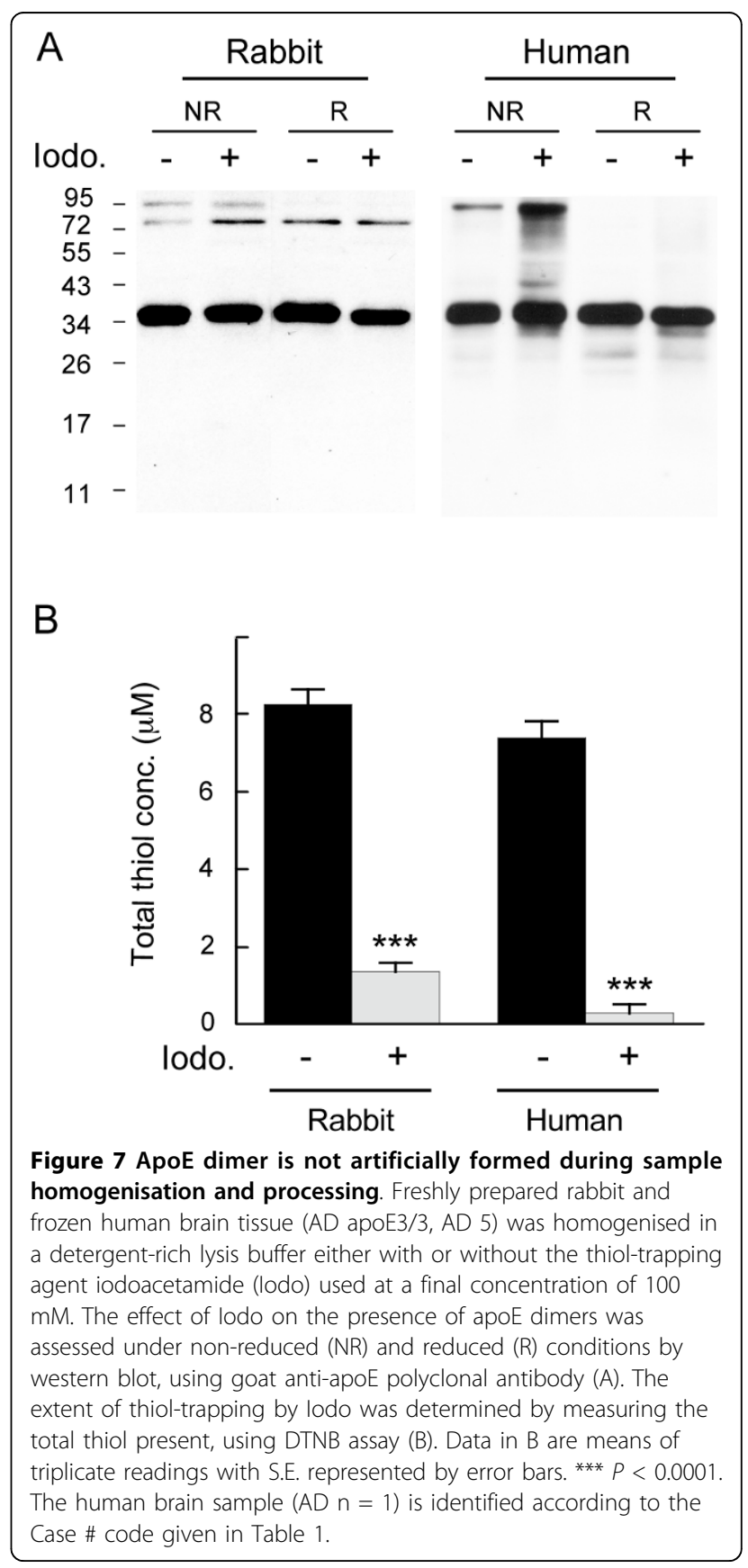


spectrophotometric analysis of the total thiol concentration of the homogenates using Ellman's reagent (5,5'Dithio-bis(2-nitrobenzoic acid)). The total thiol concentration was significantly reduced in both rabbit and human brain homogenates ( $84 \%$ and $96 \%$, respectively) treated with iodoacetamide (Fig 7B). This data demonstrates that apoE dimers are not artificially formed during tissue homogenization and processing, and further indicates that apoE dimers are generated in the brain.

\section{Discussion}

This study demonstrates for the first time that apoE3 disulphide-linked dimers are present in human frontal cortex and hippocampus. Furthermore, strikingly similar dimers were also detected in human neuroblastoma cells expressing apoE3 and in freshly prepared rabbit brain. These data indicate that apoE3 dimerisation is a physiologically relevant process in the human brain; as it is in human CSF and plasma [30,33]. The biological functions of these apoE dimers in the brain is not yet clear, however, several studies support the possibility that they may have distinct properties that differ from apoE monomer. Previous studies have demonstrated that apoE3 homodimers and apoE3-apoA-II heterodimers have diminished low-density lipoprotein receptor binding activity (20\% and $30 \%$, respectively) in comparison to apoE3 monomer $[30,35]$. In vitro studies have shown that the apoE-apoAII dimer is more effective than apoE monomer in binding soluble $A \beta 1-42$ and inhibiting its internalisation by neurons $[36,37]$. In addition, a recent study has demonstrated that the apoE3 homodimer is more effective than monomeric apoE3 at enhancing ABCA1-dependent lipid efflux from neurons [38].

Based on these data, it seems possible that the reported physiological properties of apoE dimers may enhance some of the $\mathrm{AD}$-protective functions attributed to apoE3. For example, the role of apoE in $A \beta$ clearance and degradation $[18,20]$ may be facilitated by enhanced binding with $A \beta 1-42$ [37]. In addition, the enhanced neuronal cholesterol efflux that is induced by apoE dimers as compared to monomers [38] may be important considering that high levels of neuronal cholesterol can influence processing of the amyloid precursor protein and increase $A \beta$ production [44-47]. Thus dimerisation may represent one mechanism by which apoE3 and apoE2 have a distinct $\mathrm{AD}$-protective advantage over apoE4. However, this feature alone is probably not the crucial regulator underlying apoE genotype-associated risk as the dimers were detectable at similar levels in apoE3 homozygous control and AD samples.

\section{Conclusion}

In conclusion, the presence of apoE3 dimers in the human brain represents a fundamental structural difference between apoE3 and apoE4. A greater understanding of the biological consequences of this difference may shed light on the isoform-dependent influences of apoE on AD risk.

\section{Methods}

\section{Human brain tissue}

Brain tissue samples were obtained through the Australian Brain Donor Program with ethics approval from the University of New South Wales Human Research Ethics Committee (approval No. HREC03322). The research was carried out in compliance with the Helsinki Declaration. Cortical neuritic plaques and neurofibrillary tangles were assessed according to current international standards in order to pathologically confirm the diagnosis of AD post-mortem $[48,49]$. Sample details are provided in Table 1.

\section{Human tissue preparation}

Samples were taken from the frontal cortex or hippocampus; both areas that are affected by AD [50]. The homogenisation protocol was previously described in detail [29], and was used for all samples unless stated otherwise. In brief, between $60-90 \mathrm{mg}$ of brain tissue was homogenized with a pre-chilled $1 \mathrm{~mL}$ glass dounce homogenizer, using 15 volumes of ice-cold tris-buffered saline (TBS) pH 7.4. Protease and phosphatase inhibitors (Calbiochem, San Diego, USA) were added to all samples except those to be used in experiments requiring enzyme addition (samples C6, AD5 and AD6). After centrifugation at $16,000 \mathrm{~g}$ for 25 minutes at $4{ }^{\circ} \mathrm{C}$ the TBS-soluble supernatant fraction was collected. Where specified, the pellet was then washed with $50 \mu \mathrm{L}$ of TBS and centrifuged again for $5 \mathrm{~min}$, the supernatant was then discarded and pellet was resuspended in 15 volumes of TBS containing protease and phosphatase inhibitors and $1 \%(\mathrm{w} / \mathrm{v})$ Triton X-100 (TBS-X) by pipetting up and down. Samples were then mixed by rotation for $30 \mathrm{~min}$ at $4^{\circ} \mathrm{C}$, followed by centrifugation at $16,000 \mathrm{~g}$ for $25 \mathrm{~min}$ at $4^{\circ} \mathrm{C}$ and collection of the TBS-X soluble supernatant fraction.

A second protocol was also used, where specified, to homogenise brain tissue in a detergent-rich lysis buffer. In brief, brain tissue was homogenized with a pre-chilled $1 \mathrm{~mL}$ glass dounce homogenizer, using 10 volumes of DRLB (50 mM Tris- $\mathrm{HCl}, \mathrm{pH} 8.0,150 \mathrm{mM} \mathrm{NaCl}, 0.1 \%$ SDS, 0.5\% IGEPAL CA-630, 0.5\% sodium deoxycholate) with protease and phosphatase inhibitors and either with or without $100 \mathrm{mM}$ iodoacetamide (Sigma) to trap thiol groups and thus prevent changes in disulphide bond status during homogenization and sample processing [51]. Homogenates were then centrifuged at 16,000 $\mathrm{g}$ for $10 \mathrm{~min}$ at $4^{\circ} \mathrm{C}$ in an Eppendorf 5417-R refrigerated Microfuge and the supernatants collected. 
Table 1 Brain donor information

\begin{tabular}{|c|c|c|c|c|c|c|c|}
\hline Case \# & Diagnosis & Sex & APOE genotype & Age at death & PMI & Brain regions analysed & ApoE homodimer as $\%$ of total apoE \\
\hline CON 1 & Normal & $\mathrm{F}$ & $\epsilon 3 / \epsilon 3$ & 73 & 60 & $\mathrm{FC} ; \mathrm{H}$ & $23.5 ; 11.4$ \\
\hline CON 2 & Normal & $\mathrm{F}$ & $\epsilon 3 / \epsilon 3$ & 83 & 24 & $\mathrm{FC} ; \mathrm{H}$ & $21.3 ; 9.1$ \\
\hline CON 3 & Normal & $\mathrm{F}$ & $\epsilon 3 / \epsilon 3$ & 77 & 36 & FC & 4.2 \\
\hline CON 4 & Normal & M & $\epsilon 3 / \epsilon 3$ & 79 & 60 & $\mathrm{FC} ; \mathrm{H}$ & $16.7 ; 10$ \\
\hline CON 5 & Normal & M & $\epsilon 3 / \epsilon 3$ & 82 & 43 & $\mathrm{FC} ; \mathrm{H}$ & $33.4 ; 6.6$ \\
\hline CON 6 & Normal & $\mathrm{F}$ & $\epsilon 3 / \epsilon 3$ & 93 & 21 & $\mathrm{FC} ; \mathrm{H}$ & $2.47 ; 6.15$ \\
\hline CON 7 & Normal & $\mathrm{F}$ & $\epsilon 3 / \epsilon 3$ & 85 & 23 & $\mathrm{FC} ; \mathrm{H}$ & $13.73 ; 6.75$ \\
\hline AD 1 & $A D$ & $\mathrm{~F}$ & $\epsilon 3 / \epsilon 3$ & 79 & 4 & $\mathrm{FC}$ & 4.4 \\
\hline AD 2 & $A D$ & M & $\epsilon 3 / \epsilon 3$ & 60 & 2 & FC & 10.4 \\
\hline AD 3 & $A D$ & M & $\epsilon 3 / \epsilon 3$ & 75 & 1 & $\mathrm{FC}$ & 19.13 \\
\hline AD 4 & $A D$ & M & $\epsilon 3 / \epsilon 3$ & 70 & 35 & $\mathrm{FC} ; \mathrm{H}$ & $12.55 ; 7.56$ \\
\hline AD 5 & $A D$ & $\mathrm{~F}$ & $\epsilon 3 / \epsilon 3$ & 94 & 7 & $\mathrm{FC} ; \mathrm{H}$ & $9.54 ; 12.16$ \\
\hline AD 6 & $A D$ & $\mathrm{~F}$ & $\epsilon 3 / \epsilon 4$ & 83 & 3 & $\mathrm{FC}$ & 3.61 \\
\hline AD 7 & $A D$ & M & $\epsilon 3 / \epsilon 4$ & 73 & 16 & FC & 2.28 \\
\hline AD 8 & FAD & $F$ & $\epsilon 3 / \epsilon 4$ & 47 & 69 & FC & 4.94 \\
\hline AD 9 & FAD & M & $\epsilon 3 / \epsilon 4$ & 51 & 5 & FC & 5.2 \\
\hline AD 10 & $A D$ & M & $\epsilon 3 / \epsilon 4$ & 83 & 36 & $\mathrm{FC}$ & 5.88 \\
\hline AD 11 & $A D$ & M & $\epsilon 4 / \epsilon 4$ & 74 & 5 & $\mathrm{FC} ; \mathrm{H}$ & 0 \\
\hline AD 12 & $A D$ & $\mathrm{~F}$ & $\epsilon 4 / \epsilon 4$ & 75 & 80 & $\mathrm{FC}$ & 0 \\
\hline AD 13 & $A D$ & $\mathrm{~F}$ & $\epsilon 4 / \epsilon 4$ & 68 & 44 & FC & 0 \\
\hline AD 14 & $A D$ & M & $\epsilon 4 / \epsilon 4$ & 83 & 25 & FC & 0 \\
\hline AD 15 & $A D$ & $\mathrm{~F}$ & $\epsilon 4 / \epsilon 4$ & 78 & 24 & FC & 0 \\
\hline AD 16 & $A D$ & M & $\epsilon 4 / \epsilon 4$ & 67 & 60 & FC & 0 \\
\hline AD 17 & $A D$ & $\mathrm{~F}$ & $\epsilon 4 / \epsilon 4$ & 84 & 74 & FC & 0 \\
\hline
\end{tabular}

Brain donor information (AD, Alzheimer's disease; FAD, familial Alzheimer's disease; C, control; PMI, post-mortem interval (hours); $H$, hippocampus; FC, frontal cortex)

\section{Rabbit tissue preparation}

An adult male Watanabe rabbit was euthanased via cardiac puncture using $5 \mathrm{~mL}$ Lethabarb $(1 \mathrm{~mL}$ per 2 kg body weight, Virbac, Sydney, Australia) and the brain surgically removed to dry ice and processed immediately in order to eliminate post-mortem delay. Approximately $100 \mathrm{mg}$ of tissue was removed from the cerebral cortex, all visible vasculature was removed and the sample was rinsed three times in ice-cold phosphate-buffered saline (PBS). The sample was then homogenized following the protocol used above for the human samples.

\section{ApoE genotyping}

Genomic DNA was extracted from brain tissue and $A P O E$ amplified by PCR. Briefly, each reaction $(50 \mu \mathrm{L})$ contained $200 \mathrm{nM}$ of each primer (Invitrogen, Carlsbad, CA) 5'-TCCAAGGAGCTGCAGGCGGCGCA-3' (forward) and 5'-ACAGAATTCGCCCCGGCCTGGTACACTGCCA-3' (reverse), $2 \mathrm{mM}$ dNTPs, $2 \mathrm{mM} \mathrm{MgCl} 2$, $2 \mathrm{U}$ Taq polymerase (PCR reagents supplied by Promega, Madison, WI) and $400 \mathrm{ng}$ DNA, all combined in nuclease free $\mathrm{H}_{2} \mathrm{O}$. Amplification was carried out with 38 cycles of denaturation $\left(95^{\circ} \mathrm{C}, 30 \mathrm{sec}\right)$, annealing $\left(60^{\circ}\right.$
C, $30 \mathrm{sec})$ and extension $\left(70^{\circ} \mathrm{C}, 30 \mathrm{sec}\right)$. The $244 \mathrm{bp}$ PCR product was purified using the QIAquick PCR purification kit (Qiagen, Venlo, Netherlands), following the manufacturer's protocol, and eluted in $40 \mu \mathrm{L} \mathrm{H} \mathrm{H}_{2} \mathrm{O}$. Endonuclease restriction digests $(25 \mu \mathrm{L})$ were performed on $15 \mu \mathrm{L}$ of eluted DNA using either AflIII ( $5 \mathrm{U}$ ) or HaeII $(20 \mathrm{U})$ in the presence of BSA $(100 \mu \mathrm{g} / \mathrm{mL})$ and the supplied buffer (New England Biolabs, Ipswich, MA) at $37^{\circ} \mathrm{C}$ for $16 \mathrm{~h}$. The $\varepsilon 3$ allele is resistant to both enzymes while $\varepsilon 4$ is cleaved by AflIII (producing a 190 bp product) and $\varepsilon 2$ is cleaved by HaeII (producing a 191 bp product) assessed using ethidium bromide stained $8 \%$ polyacrylamide gels.

\section{SK-N-SH neuroblastoma cell culture}

Cell culture media and additives were from Invitrogen (Melbourne, Australia). Human neuronal SK-N-SH cells were routinely grown in DMEM, $10 \%(\mathrm{v} / \mathrm{v})$ fetal calf serum (FCS), $2 \mathrm{mM}$ glutamine, and $100 \mathrm{IU} / \mathrm{ml}$ penicillin and $100 \mu \mathrm{g} / \mathrm{ml}$ streptomycin. Cultures were grown in 75 $\mathrm{cm}^{2}$ flasks at $37^{\circ} \mathrm{C}$ in $5 \% \mathrm{CO}_{2}$ and plated into 6-well plates for use in experiments. To induce apoE expression, SK-N-SH cells were cultured under serum starved conditions ( 5 days of culture without media 
replenishment) and harvested in cell lysis buffer $(10 \mathrm{mM}$ Tris- $\mathrm{HCl}, 10 \mathrm{mM} \mathrm{Na}{ }_{2} \mathrm{PO}_{4} / \mathrm{NaHPO}_{4}, \mathrm{pH} 7.5,130 \mathrm{mM}$ $\mathrm{NaCl}, 1 \%$ Triton-X-100, $10 \mathrm{mM} \mathrm{NaPP}$ ) as described previously [11]. SK-N-SH cells have been shown to be apoE3/3 homozygous [42,43].

\section{Western blotting}

Bicinchoninic acid protein assays were performed on brain homogenate samples and equal amounts of protein were separated on $12 \%$ SDS-PAGE gels and transferred onto $0.45 \mu \mathrm{m}$ nitrocellulose membranes at $100 \mathrm{~V}$ for $30 \mathrm{~min}$. Membranes were Ponceau-stained and scanned before blocking overnight at $4^{\circ} \mathrm{C}$ in PBS containing $5 \%(\mathrm{w} / \mathrm{v})$ non-fat dry milk. The membranes were then probed with the relevant antibodies at $22^{\circ} \mathrm{C}$ for $1 \mathrm{~h}$ to reveal the bands of interest. Concentrations of antibodies were: goat polyclonal anti-human apoE 1/5000 (Calbiochem) or mouse monoclonal anti-human apoE 21-F3-D2 1/1000 (Biogenesis, Poole, UK). The membranes were washed three times in PBS containing 0.1\% $(\mathrm{w} / \mathrm{v})$ Tween-20 and then incubated with horseradish peroxidase-conjugated rabbit anti-goat (Dako, 1/2500) or rabbit anti-mouse (Dako, 1/1000) secondary antibody for $1 \mathrm{~h}$. The proteins of interest were detected using enhanced chemiluminescence (ECL, Amersham Biosciences) and X-ray film. Signal intensity was quantified using Image-J software. Specifically, a fixed area was used to separately measure signal intensity from i) the region encompassing intact $\sim 34 \mathrm{kDa}$ and fragmented $\sim 24 \mathrm{kDa}$ apoE, ii) apoE homodimer at $\sim 95 \mathrm{kDa}$, and iii) an adjacent blank region to serve as a background control. The background value (iii) was subtracted from the apoE measurements ( $\mathrm{i}$ and ii) and the homodimer quantification was expressed as a percentage of total apoE. Where possible, relative differences between samples were assessed on the same blots or using simultaneously processed gels with identical film exposure times.

\section{Enzymatic treatment of brain homogenates}

Thrombin digestion was performed by incubating brain homogenates $(30 \mu \mathrm{g}$ of protein) prepared in the absence of protease inhibitors with $4.5 \mathrm{U}$ of thrombin (Sigma, St. Louis, MO) in PBS at $37^{\circ} \mathrm{C}$ for 16 hours. Two control conditions were also analysed: homogenates either stored at $-80^{\circ} \mathrm{C}$ for the incubation period or incubated with thrombin that was heat-inactivated at $95^{\circ} \mathrm{C}$ for 15 minutes.

\section{Thiol quantification}

The concentration of total thiol groups, both proteinbound and free, in specified brain homogenates was determined using 5,5'-dithio-bis(2-nitrobenzoic acid) (DTNB, Sigma) also known as 'Ellman's Reagent' as described previously [52]. Briefly, a $30 \mu \mathrm{L}$ volume of brain homogenate (either undiluted or diluted in homogenisation buffer) was combined with $75 \mu \mathrm{L}$ of dilution buffer (30 mM Tris $\mathrm{HCl}, 3 \mathrm{mM}$ EDTA pH 8.2), $25 \mu \mathrm{L}$ of DTNB reagent $(1.19 \mathrm{mg} / \mathrm{mL}$ DTNB in methanol) and $400 \mu \mathrm{L}$ methanol. Samples were centrifuged at $3000 \mathrm{~g}$ for $5 \mathrm{~min}$ at room temperature. $3 \times 90 \mu \mathrm{L}$ aliquots of supernatant were collected and absorbance was measured at $415 \mathrm{~nm}$. Thiol concentration was determined by reference to a cysteine (Sigma) standard curve.

\section{Abbreviations}

A $\beta$ : amyloid- $\beta$; AD: Alzheimer's disease; apoE: apolipoprotein-E; CNS: central nervous system; Con: control; CSF: cerebrospinal fluid; DTNB: 5,5'-Dithio-bis(2nitrobenzoic acid); HI-Thr: heat-inactivated thrombin; lodo: iodoacetamide; NR: non-reduced; PAGE: polyacrylamide gel electrophoresis; PBS: phosphate buffered saline; PMI: post-mortem interval; R: reduced; SDS: sodium dodecyl sulfate; TBS: tris buffered saline; TBS-X: TBS containing 1\% (w/V) Triton X-100; Thr: thrombin.

\section{Acknowledgements}

Human brain tissue samples were received from the Australian Brain Donor Program, Prince of Wales Medical Research Institute Brain Bank, which is supported by the Australian National Health and Medical Research Council (NHMRC). This work was supported by a Viertel Foundation Postdoctoral Fellowship in Dementia awarded to DE by Alzheimer's Australia. GH and BG are supported by Fellowships from the NHMRC and the Australian Research Council.

\section{Author details}

'Prince of Wales Medical Research Institute, Randwick NSW 2031, Australia. ${ }^{2}$ School of Medical Sciences, Faculty of Medicine, University of New South Wales, Sydney NSW 2052, Australia. ${ }^{3}$ School of Biological Sciences, University of Wollongong, Wollongong NSW 2522, Australia.

\section{Authors' contributions}

DE carried out the experimental work, performed the statistical analysis and drafted the manuscript. GH collected and provided human brain tissues. BG conceived of the study, participated in its design and coordination and prepared the final manuscript. All authors read and approved the final manuscript.

Received: 26 August 2009

Accepted: 20 February 2010 Published: 20 February 2010

\section{References}

1. Mahley RW: Apolipoprotein E: cholesterol transport protein with expanding role in cell biology. Science 1988, 240:622-630.

2. Ladu MJ, Reardon C, Van Eldik L, Fagan AM, Bu G, Holtzman D, Getz GS: Lipoproteins in the central nervous system. Ann N Y Acad Sci 2000, 903:167-175.

3. Rall SC Jr, Weisgraber KH, Innerarity TL, Mahley RW: Structural basis for receptor binding heterogeneity of apolipoprotein E from type III hyperlipoproteinemic subjects. Proc Natl Acad Sci USA 1982, 79:4696-4700.

4. Corder EH, Saunders AM, Strittmatter WJ, Schmechel DE, Gaskell PC, Small GW, Roses AD, Haines JL, Pericak-Vance MA: Gene dose of apolipoprotein E type 4 allele and the risk of Alzheimer's disease in late onset families. Science 1993, 261:921-923.

5. Strittmatter WJ, Saunders AM, Schmechel D, Pericak-Vance M, Enghild J, Salvesen GS, Roses AD: Apolipoprotein E: high-avidity binding to betaamyloid and increased frequency of type 4 allele in late-onset familial Alzheimer disease. Proc Natl Acad Sci USA 1993, 90:1977-1981.

6. LaDu MJ, Gilligan SM, Lukens JR, Cabana VG, Reardon CA, Van Eldik LJ, Holtzman DM: Nascent astrocyte particles differ from lipoproteins in CSF. I Neurochem 1998, 70:2070-2081.

7. Xu Q, Li Y, Cyras C, Sanan DA, Cordell B: Isolation and characterization of apolipoproteins from murine microglia. Identification of a low density lipoprotein-like apolipoprotein J-rich but E-poor spherical particle. J Biol Chem 2000, 275:31770-31777. 
8. Xu PT, Gilbert JR, Qiu HL, Ervin J, Rothrock-Christian TR, Hulette C, Schmechel DE: Specific regional transcription of apolipoprotein E in human brain neurons. Am J Pathol 1999, 154:601-611.

9. Boschert U, Merlo-Pich E, Higgins G, Roses AD, Catsicas S: Apolipoprotein E expression by neurons surviving excitotoxic stress. Neurobiol Dis 1999, 6:508-514

10. Metzger RE, LaDu MJ, Pan JB, Getz GS, Frail DE, Falduto MT: Neurons of the human frontal cortex display apolipoprotein $\mathrm{E}$ immunoreactivity: implications for Alzheimer's disease. J Neuropathol Exp Neurol 1996, 55:372-380.

11. Elliott DA, Kim WS, Jans DA, Garner B: Apoptosis induces neuronal apolipoprotein-E synthesis and localization in apoptotic bodies. Neurosci Lett 2007, 416:206-210.

12. Mahley RW, Nathan BP, Pitas RE: Apolipoprotein E. Structure, function, and possible roles in Alzheimer's disease. Ann N Y Acad Sci 1996, 777:139-145.

13. Miyata M, Smith JD: Apolipoprotein E allele-specific antioxidant activity and effects on cytotoxicity by oxidative insults and beta-amyloid peptides. Nat Genet 1996, 14:55-61.

14. Strittmatter WJ, Weisgraber KH, Goedert M, Saunders AM, Huang D, Corder EH, Dong LM, Jakes R, Alberts MJ, Gilbert JR, et al: Hypothesis: microtubule instability and paired helical filament formation in the Alzheimer disease brain are related to apolipoprotein E genotype. Exp Neurol 1994, 125:163-171, discussion 172-164.

15. Mahley RW, Rall SC Jr: Apolipoprotein E: far more than a lipid transport protein. Annu Rev Genomics Hum Genet 2000, 1:507-537.

16. Arai H, Kashiwagi S, Nagasaka Y, Uchida K, Hoshii Y, Nakamura K: Oxidative modification of apolipoprotein $E$ in human very-low-density lipoprotein and its inhibition by glycosaminoglycans. Arch Biochem Biophys 1999, $367: 1-8$

17. Jordan J, Galindo MF, Miller RJ, Reardon CA, Getz GS, LaDu MJ: Isoformspecific effect of apolipoprotein $E$ on cell survival and beta-amyloidinduced toxicity in rat hippocampal pyramidal neuronal cultures. $J$ Neurosci 1998, 18:195-204.

18. Beffert U, Aumont N, Dea D, Lussier-Cacan S, Davignon J, Poirier J: Apolipoprotein $\mathrm{E}$ isoform-specific reduction of extracellular amyloid in neuronal cultures. Brain Res Mol Brain Res 1999, 68:181-185.

19. Bell RD, Sagare AP, Friedman AE, Bedi GS, Holtzman DM, Deane R, Zlokovic BV: Transport pathways for clearance of human Alzheimer's amyloid beta-peptide and apolipoproteins $\mathrm{E}$ and $\mathrm{J}$ in the mouse central nervous system. J Cereb Blood Flow Metab 2007, 27:909-918.

20. Jiang Q, Lee CY, Mandrekar S, Wilkinson B, Cramer P, Zelcer N, Mann K, Lamb B, Willson TM, Collins JL, et al: ApoE promotes the proteolytic degradation of Abeta. Neuron 2008, 58:681-693.

21. Xu Q, Brecht WJ, Weisgraber KH, Mahley RW, Huang Y: Apolipoprotein E4 domain interaction occurs in living neuronal cells as determined by fluorescence resonance energy transfer. J Biol Chem 2004, 279:25511-25516.

22. LaDu MJ, Falduto MT, Manelli AM, Reardon CA, Getz GS, Frail DE: Isoformspecific binding of apolipoprotein E to beta-amyloid. J Biol Chem 1994, 269:23403-23406.

23. Tokuda T, Calero M, Matsubara E, Vidal R, Kumar A, Permanne B, Zlokovic B, Smith JD, Ladu MJ, Rostagno A, et al: Lipidation of apolipoprotein E influences its isoform-specific interaction with Alzheimer's amyloid beta peptides. Biochem J 2000, 348(Pt 2):359-365.

24. Morrow JA, Segall ML, Lund-Katz S, Phillips MC, Knapp M, Rupp B Weisgraber KH: Differences in stability among the human apolipoprotein E isoforms determined by the amino-terminal domain. Biochemistry 2000, 39:11657-11666.

25. Clement-Collin V, Barbier A, Dergunov AD, Visvikis A, Siest G, Desmadril M, Takahashi M, Aggerbeck LP: The structure of human apolipoprotein E2, $\mathrm{E} 3$ and $\mathrm{E} 4$ in solution. 2. Multidomain organization correlates with the stability of apoE structure. Biophys Chem 2006, 119:170-185.

26. Marques MA, Tolar M, Harmony JA, Crutcher KA: A thrombin cleavage fragment of apolipoprotein $E$ exhibits isoform-specific neurotoxicity. Neuroreport 1996, 7:2529-2532.

27. Tolar M, Marques MA, Harmony JA, Crutcher KA: Neurotoxicity of the 22 $\mathrm{kDa}$ thrombin-cleavage fragment of apolipoprotein $\mathrm{E}$ and related synthetic peptides is receptor-mediated. J Neurosci 1997, 17:5678-5686.

28. Huang Y, Liu XQ, Wyss-Coray T, Brecht WJ, Sanan DA, Mahley RW: Apolipoprotein E fragments present in Alzheimer's disease brains induce neurofibrillary tangle-like intracellular inclusions in neurons. Proc Natl Acad Sci USA 2001, 98:8838-8843.

29. Elliott DA, Tsoi K, Holinkova S, Chan SL, Kim WS, Halliday GM, Rye KA, Garner B: Isoform-specific proteolysis of apolipoprotein-E in the brain. Neurobiol Aging 2010.

30. Weisgraber KH, Shinto LH: Identification of the disulfide-linked homodimer of apolipoprotein E3 in plasma. Impact on receptor binding activity. J Biol Chem 1991, 266:12029-12034.

31. LaDu MJ, Lukens JR, Reardon CA, Getz GS: Association of human, rat, and rabbit apolipoprotein E with beta-amyloid. J Neurosci Res 1997, 49:9-18.

32. Montine KS, Bassett CN, Ou JJ, Markesbery WR, Swift LL, Montine TJ: Apolipoprotein E allelic influence on human cerebrospinal fluid apolipoproteins. J Lipid Res 1998, 39:2443-2451.

33. Rebeck GW, Alonzo NC, Berezovska O, Harr SD, Knowles RB, Growdon JH, Hyman BT, Mendez AJ: Structure and functions of human cerebrospinal fluid lipoproteins from individuals of different APOE genotypes. Exp Neurol 1998, 149:175-182.

34. Sun Y, Wu S, Bu G, Onifade MK, Patel SN, LaDu MJ, Fagan AM, Holtzman DM: Glial fibrillary acidic protein-apolipoprotein E (apoE) transgenic mice: astrocyte-specific expression and differing biological effects of astrocyte-secreted apoE3 and apoE4 lipoproteins. J Neurosci 1998, 18:3261-3272.

35. Innerarity TL, Mahley RW, Weisgraber KH, Bersot TP: Apoprotein (E-A-II) complex of human plasma lipoproteins. II. Receptor binding activity of a high density lipoprotein subfraction modulated by the apo(E-A-II) complex. J Biol Chem 1978, 253:6289-6295.

36. Yamauchi K, Tozuka M, Hidaka H, Nakabayashi T, Sugano M, Kondo Y, Nakagawara A, Katsuyama T: Effect of apolipoprotein All on the interaction of apolipoprotein $\mathrm{E}$ with beta-amyloid: some apo(E-All) complexes inhibit the internalization of beta-amyloid in cultures of neuroblastoma cells. J Neurosci Res 2000, 62:608-614.

37. Yamauchi K, Tozuka M, Nakabayashi T, Sugano M, Hidaka H, Kondo Y, Katsuyama T: Higher avidity binding of apolipoprotein (E-All) complex than of apolipoprotein E monomer to beta-amyloid. J Neurosci Res 1999, 58:301-307.

38. Minagawa $\mathrm{H}$, Gong JS, Jung CG, Watanabe A, Lund-Katz S, Phillips MC, Saito H, Michikawa M: Mechanism underlying apolipoprotein E (ApoE) isoform-dependent lipid efflux from neural cells in culture. J Neurosci Res 2009, 87:2498-2508.

39. Bradley WA, Gilliam EB, Gotto AM Jr, Gianturco SH: Apolipoprotein-E degradation in human very low density lipoproteins by plasma protease (s): chemical and biological consequences. Biochem Biophys Res Commun 1982, 109:1360-1367.

40. Bode W: Structure and interaction modes of thrombin. Blood Cells Mol Dis 2006, 36:122-130.

41. Huntington JA: Molecular recognition mechanisms of thrombin. J Thromb Haemost 2005, 3:1861-1872.

42. Caillet-Boudin ML, Dupont-Wallois L, Soulie C, Delacourte A: Apolipoprotein $\mathrm{E}$ and Tau phosphorylation in human neuroblastoma cells. Neurosci Lett 1998, 250:83-86.

43. Dupont-Wallois L, Soulie C, Sergeant N, Wavrant-de Wrieze N, ChartierHarlin MC, Delacourte A, Caillet-Boudin ML: ApoE synthesis in human neuroblastoma cells. Neurobiol Dis 1997, 4:356-364.

44. Simons M, Keller P, De Strooper B, Beyreuther K, Dotti CG, Simons K Cholesterol depletion inhibits the generation of beta-amyloid in hippocampal neurons. Proc Natl Acad Sci USA 1998, 95:6460-6464.

45. Runz H, Rietdorf J, Tomic I, de Bernard M, Beyreuther K, Pepperkok R, Hartmann T: Inhibition of intracellular cholesterol transport alters presenilin localization and amyloid precursor protein processing in neuronal cells. J Neurosci 2002, 22:1679-1689.

46. Kim WS, Suryo Rahmanto A, Kamili A, Rye KA, Guillemin GJ, Gelissen IC, Jessup W, Hill AF, Garner B: Role of ABCG1 and ABCA1 in regulation of neuronal cholesterol efflux to apolipoprotein-E discs and suppression of amyloid-beta peptide generation. J Biol Chem 2007, 282:2851-2861.

47. Kim WS, Weickert CS, Garner B: Role of ATP-binding cassette transporters in brain lipid transport and neurological disease. J Neurochem 2008, 104:1145-1166.

48. Mirra SS, Heyman A, McKeel D, Sumi SM, Crain BJ, Brownlee LM, Vogel FS, Hughes JP, van Belle G, Berg L: The Consortium to Establish a Registry for Alzheimer's Disease (CERAD). Part II. Standardization of the 
neuropathologic assessment of Alzheimer's disease. Neurology 1991, 41:479-486.

49. NIA: Consensus recommendations for the postmortem diagnosis of Alzheimer's disease. The National Institute on Aging, and Reagan Institute Working Group on Diagnostic Criteria for the Neuropathological Assessment of Alzheimer's Disease. Neurobiol Aging 1997, 18:S1-2.

50. West MJ, Coleman PD, Flood DG, Troncoso JC: Differences in the pattern of hippocampal neuronal loss in normal ageing and Alzheimer's disease. Lancet 1994, 344:769-772.

51. Furukawa Y, Fu R, Deng HX, Siddique T, O'Halloran TV: Disulfide crosslinked protein represents a significant fraction of ALS-associated $\mathrm{Cu}, \mathrm{Zn}$ superoxide dismutase aggregates in spinal cords of model mice. Proc Natl Acad Sci USA 2006, 103:7148-7153.

52. Ellman GL: Tissue sulfhydryl groups. Arch Biochem Biophys 1959, 82:70-77.

\section{doi:10.1186/1471-2202-11-23}

Cite this article as: Elliott et al: Apolipoprotein-E forms dimers in

human frontal cortex and hippocampus. BMC Neuroscience 2010 11:23.

\section{Submit your next manuscript to BioMed Central} and take full advantage of:

- Convenient online submission

- Thorough peer review

- No space constraints or color figure charges

- Immediate publication on acceptance

- Inclusion in PubMed, CAS, Scopus and Google Scholar

- Research which is freely available for redistribution

Submit your manuscript at www.biomedcentral.com/submit 